\title{
TUDO PODE SER MOTIVO - ROSE AUSLÄNDER
}

\section{EVERYTHING CAN BE A MOTIF - ROSE AUSLÄNDER}

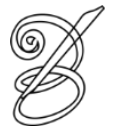 \\ Traduzido por: \\ Luiz Carlos ABDALA JUNIOR*
}

Resumo: A tradução a seguir verte para o português um dos textos mais importantes de Rose Ausländer: "Tudo pode ser motivo" (Alles kann Motiv sein), de 1971. Reconhecida como importante poeta de língua alemã da segunda metade do século XX, Rose Ausländer deixou também uma obra em prosa, escrevendo textos de caráter ensaístico com alta carga poética. Entre estes, "Tudo pode ser motivo" ocupa lugar especial, pois nele encontramos um gesto metaliterário de Ausländer ao tematizar o seu próprio fazer poético enquanto motivo, que como o título já antecipa, é um dos tantos motivos que a potência do poema possibilita. O texto abre a maior coletânea da poesia da autora até aqui, organizada pelo editor Helmut Braun e publicada em 2012 pela S. Fischer Verlag.

Palavras-chave: Rose Ausländer; Tudo pode ser motivo; Literatura de língua alemã; Literatura de exílio; Tradução.

Abstract: The following translation brings into Portuguese one of Rose Ausländer's most important texts: "Everything can be a motif" (Alles kann Motiv sein), from the year 1971. Recognized as an important Germanspeaking poet of the second half of the 20th century, Rose Ausländer also left a prose work composed by writing essays of a highly poetic nature. Among these, "Everything can be a motif" occupies a special place, once we find in it a metaliterary gesture by Ausländer in the thematization of her own poetic making as a motive, which, as the title already anticipates, is one of the many motives that the potency of the poem enables. The text opens the largest compilation of the author's poetry so far, organized by editor Helmut Braun and published in 2012 by S. Fischer Verlag.

Keywords: Rose Ausländer; Everything can be a motif; German language literature; Exile literature; Translation.

RECEBIDO EM: 8 de outubro 2019

ACEITO EM: 25 de novembro 2019

PUBLICADO EM: março 2020 
$\mathbf{S}$ obre a autora: Rose Ausländer (1901-1988) é uma escritora de língua alemã nascida em Czernowitz, Bucovina. De origem judaica, sofreu perseguição nazista durante a Segunda Guerra Mundial e exilou-se nos Estados Unidos, onde passou a escrever em inglês. Alguns anos depois, retorna à língua materna e também a Europa, passando a viver em Düsseldorf até o falecimento. Sua obra, reunindo poemas e textos em prosa, está hoje publicada pela S. Fischer Verlag.

Sobre o texto: Se há casos em que podemos ler um(a) poeta por outro lugar que não a sua própria poesia, "Tudo pode ser motivo" é um deles. Publicado em 1971, aqui encontramos um dos escritos mais potentes Rose Ausländer, onde a autora põe em diálogo a criação poética com a memória e a formação da identidade. Para ela, escrever não era somente legar as palavras ao papel, mas também permitir que as palavras atuem sobre quem escreve. Nessa simbiose entre escrita e vida, as experiências pessoais e poéticas multiplicam seus sentidos e intensificam suas possíveis interlocuções, sem que uma determine a outra. Estão articuladas neste texto a reflexão de Ausländer sobre a criação poética e sua relação sensível com a

palavra e a língua, materna ou estrangeira, com as experiências históricas que constituíram o pano de fundo desta vivência e construção narrativa individual. "Tudo pode ser motivo" pode ser lido como um texto síntese da obra da autora, não por apenas conter em alguns parágrafos vários dos elementos que orbitam a imagética da poeta, mas também por, a partir da aproximação entre eles e reflexão promovida, potencializar possíveis chaves de leitura para esta mesma obra.

\section{Tudo pode ser motivo ${ }^{1}$}

Por que eu escrevo?

Porque as palavras me ditam: nos escreva. Elas querem estar vinculadas, aliadas. Palavra com palavra com palavra. Uma falange de palavras por, outras contra, mim. Elas querem invadir o campo do papel, aí deve ser travada a batalha. Geralmente fico cética, não quero me sujeitar a sua ditadura, as arremesso ao vento. Sendo elas mais fortes que ele, voltam a mim, me agitam e atormentam, até que eu me entregue. Então, agora me deixem em paz. Mas palavras não são figuras dóceis, com que se pode fazer o que quiser. Eu teria as entendido mal, elas afirmam que quiseram dizer outra coisa. Não estão acomodadas no lugar certo, murmuram elas. Hipócritas, que pacíficas e indiferentes ficam na superfície branca. Isso é ilusão. Elas são difíceis, até as mais ternas. Nos olhamos, nos amamos. Minhas árvores, 
minhas estrelas, meus irmãos: nesse estilo converso com elas. Elas invertem o estilo, me agarram, me impelem a empurrá-las de lá para cá, até que acreditem terem tomado o seu lugar de nascimento. Por que eu escrevo? Porque eu, procurando minha identidade, falo mais claramente comigo mesma no papel em branco. Ele me tensiona. Fico curiosa pelas palavras que querem vir até mim. Falo com elas para mim, para você, te encorajo a me escutar. O mundo me faz perguntas traiçoeiras. Minhas palavras respondem com perguntas francas. Criptograficamente se desfolha minha vida, folha por folha: anos que sobre o impenetrável Onde-Aonde? fazem versos. Eu presto contas de mim, do meu entorno, da minha situação e contexto. Minhas palavras querem ser contabilizadas: débito e crédito. Você deve nos ter, elas dizem, quando nos coloca no livro. Eu resisto. Eu penso muitas poesias e histórias, mas só escrevo uma fração delas. Por quê?

Porque. Explicações são apenas uma pequena fração da verdade. Por que escrevo? Talvez porque eu vim ao mundo em Czernowitz, porque o mundo veio a mim em Czernowitz. Aquelas paisagens excepcionais. As pessoas excepcionais. Contos e mitos no ar, se pode até os respirar. A quadrilíngue Czernowitz era uma cidade musical, que abrigou muitos artistas, poetas, amantes das artes, da literatura e da filosofia. Foi o local escolhido pelo grande poeta de fábulas iídiche Elieser Steinberg. Gerou o mais significativo poeta iídiche Itzig Manger e duas gerações de poetas de língua alemã. O mais novo e mais importante foi Paul Celan, o mais velho Alfred Margum-Sperber, respeitado poeta e tradutor na Romênia e na Alemanha Oriental, que morreu em 1968 aos 69 anos. Foi ele quem me descobriu e organizou meu primeiro livro de poesia, Der Regenbogen (O arco-íris), lançado no ano de 1939 em Czernowitz. Meu interesse inicial estava na filosofia. Os filósofos ecléticos Benedikt Spinoza (que ganhava a vida trabalhando com lentes ópticas) e o grande pensador berlinense Constantin Brunner deram fundamento ao meu pensar. Um poema meu daquele tempo começa assim: "Meu Senhor se chama Benedikt. / O cosmos / Ele lapidou."2. Os posteriores ensaios sobre Spinoza, Brunner, Platão (Fedro), Freud (Medo), meus poemas em manuscrito, diários, cartas, assim como as edições de Regenbogen, se tornaram vítimas da guerra.

Com 17 anos comecei a escrever anotações, ideias, versos em um diário. Logo me ficou claro que a poesia era meu elemento vital. Por anos escrevi poemas, prosa poética, textos ritmados, também alguns contos de fadas. Alguns confiei à gaveta, o resto mandei para a lixeira. Vários poetas e escritores eram importantes para mim, mas de Hölderlin e Kafka saíram os impulsos mais duradouros. Veio uma fase de diferentes tipos de experimento com versos livres e métricos, muitos rimados. Nosso mestre da palavra Karl Kraus louvava a rima: 
"É a margem latente / do pensamento congruente."3. O adjetivo também desempenhava um papel vital. O que mais tarde se abateu sobre nós foi tão desarmonioso e descosido, pesadelo tão angustiante, que - só no rescaldo, no choque posterior inteiramente sofrido - a rima ruiu. Palavra-flor murchou. Também muitos atributos tornaram-se questionáveis em um mundo mecanizado, que pertencia ao "Homem sem qualidades", à pessoa despersonalizada. O antigo vocabulário precisou ser substituído. As estrelas - eu não pude distanciá-las da minha poesia do pós-guerra - apareciam em outra constelação.

Czernowitz 1941. Nazistas ocupam a cidade, permanecem até o começo de 1944. Gueto, miséria, horror, trens da morte. Todos os anos encontrávamos amigos, às escondidas, geralmente sob o risco de vida, para ler poemas. Na insuportável realidade existiam dois comportamentos: se entregar ao desespero ou migrar para outra realidade, a espiritual. Nós, judeus condenados à morte, éramos indizivelmente necessitados de alívio. E enquanto esperávamos pela morte, alguns de nós moravam nos verboníricos. Nosso lar traumático no meio da falta de lar. Escrever era vida. Sobrevida.

“[...] Nos barcos em fuga / flâmulas limpam do céu os sonhos [...]” — "[...] que 222 estrelas invisíveis florescem." ${ }^{4}$ Esse e outros muitos versos leu para mim um jovem rapaz que, em 1944, um amigo me apresentou: Paul Antschel-Celan. Como revanche lia eu então meus poemas mais recentes, e ele os muito elogiou.

Final de 1946. Imigração nos EUA. Luta pela existência. Reorientação. Provocação. O novo mundo da literatura norte-americana e inglesa era um excitante impulso fresco. Após anos de silêncio me surpreendi em uma noite ao escrever poesia em inglês. Um dos meus primeiros textos em inglês começava: "Looking for a final start" (Em busca de um início definitivo). Muitos poemas saíram em jornais literários estadunidenses, alguns foram transmitidos pela rádio WEVD. Por que escrevo desde 1956 novamente em alemão? Misteriosamente, como apareceu, desapareceu a musa inglesa. Nenhum outro pretexto externo causou o retorno à língua materna. Segredo do subconsciente. Só em 1957 que me familiarizei com a poesia contemporânea de língua alemã. O mundo naufragado reapareceu transformado: numa outra luz. Formas obsoletas foram deixadas nas sombras. Muito da poesia moderna alemã foi para mim de permanente significado.

1957. Duas semanas em Paris. Paul Celan me convidou várias vezes, leu para mim coisas novas, poemas que mais tarde saíram no Sprachgitter (Prisão da fala). Perguntou por meus novos trabalhos. Hesitante mostrei a ele seis textos. Ele reagiu assim que os leu: "Das unhörbare Herz, Atlantis, Ruf und Kristall e Eingeschneit são muito, muito, muito bonitos. 
Também Blinder Sommer é um belo poema.”. O sexto ele me devolveu em silêncio. Logo depois li Mohn und Gedächtnis (Ópio e memória) e Von Schwelle zu Schwelle (De limiar em limiar): um novo modelo de evocação poética. O existencialismo verbocriador de Celan era convincente. A morte chamara o seu melhor poeta à vida.

Meus temas preferidos? Todos — cada um por si mesmo. Cósmicos, Zeitkritik, paisagens, coisas, pessoas, temperamentos... Tudo pode ser motivo! No sentido do pertencimento social a minha poesia é engajada. Da singularidade e intensidade de uma experiência, um evento, resulta a forma externa e interna do texto. Frequentemente me perguntei $o$ que essa escritura realmente seria e me dei diferentes respostas. Fiquei com a mais recente: Escrever é uma pulsão. O poeta, o escritor, deve se alimentar, se movimentar, parar, pensar, sentir e escrever - escrever, o que seus pensamentos e fantasia lhe prescrevem.

Por que eu escrevo? Eu não sei.

\section{REFERÊNCIA}

AUSLÄNDER, Rose. Alles kann Motiv sein. In: Rose Ausländer - Gedicht. Org: Helmut Braun. Frankfurt am Main: Fischer Verlag, 2012, p. 7-10.

\footnotetext{
*Luiz Carlos ABDALA JUNIOR - Mestrando em Letras (Estudos Literários) na Universidade Federal do Paraná. Graduado em Letras - Português/Alemão (2019) pela mesma instituição. Universidade Federal do Paraná, Setor de Ciências Humanas, Programa de Pós-Graduação em Letras. Curitiba, Paraná, Brasil.

Currículo acadêmico: http://lattes.cnpq.br/3703453721041981

ORCID: https://orcid.org/0000-0002-8912-5576

E-mail: luizabdalajr@gmail.com

${ }^{1}$ Esta tradução foi autorizada pela S. Fischer Verlag por e-mail no dia 30/09/2019.

Rose Ausländer: Alles kann Motiv sein In: Rose Ausländer: Gedichte, hrsg. von Helmut Braun (C) S. Fischer Verlag GmbH, Frankfurt am Main 2012. By courtesy of S. Fischer Verlag GmbH, Frankfurt am Main.

2 "Mein Heiliger heißt Benedikt./Er hat das Weltall/klargeschliffen.". Todas as traduções dos trechos de poemas são de minha autoria.

3"Er ist das Ufer, wo sie landen,/sind zwei Gedanken einverstanden."

4“...Auf den flüchtenden Kähnen/löschen die Wimpel den Traum, von den Himmeln...” — "daß die unsichtbaren Gestirne aufblühen."
} 